\title{
Developing child autonomy in pediatric healthcare: towards an ethical model
}

\author{
Kyriakos Martakis, MD, MSc, ${ }^{a, b, c}$ Helmut Brand, MD, PhD and \\ Peter Schröder-Bäck, PhD ${ }^{a, d}$
}

\begin{abstract}
The changes initiated by the new National Civil and Commercial Code in Argentina underline the pediatric task to empower children's and adolescents' developing autonomy. In this paper, we have framed a model describing autonomy in child healthcare.

We carried out a literature review focusing on i) the concept of autonomy referring to the absolute value of the autonomous individual, and ii) the age-driven process of competent decisionmaking development.

We summarized our findings developing a conceptual model that includes the child, the pediatrician and the parents. The pediatricianchild relationship is based on different forms of guidance and cooperation, resulting in varying levels of activity and passivity. Parental authority influences the extent of autonomy, based on the level of respect of the child's moral equality. Contextual, existential, conceptual, and socialethical conditions shall be considered when applying the model to facilitate dialogue between pediatricians, children, parents and other actors. Key words: Adolescent; Child; Personal Autonomy; Pediatrics; Healthcare provider.
\end{abstract}

http:/ / dx.doi.org/10.5546/aap.2018.eng.e401 Institute), Maastricht University, the Netherlands

b. Children's and Adolescents' Hospital, and

c. Center of Prevention and Rehabilitation.

University Hospital of

Cologne, Cologne,

Germany

d. Faculty of Human and Health Sciences, University of Bremen, Germany

E-mail address:

Kyriakos Martakis, MD, MSc:

kyriakos.martakis@ maastrichtuniversity.nl

Funding:

None.

Conflict of interest: None.

Received: 7-18-2017

Accepted: 11-8-2017
To cite: Martakis K, Brand H, Schröder-Bäck P. Developing child autonomy in pediatric healthcare: towards an ethical model. Arch Argent Pediatr 2018;116(3):e401-e408.

\section{INTRODUCTION}

The changes initiated by the new National Civil and Commercial Code bear significant implications in the pediatric routine, according to the Subcommittee of Clinical Ethics of the Argentinean Pediatric Society (SAP). ${ }^{1}$ Children and adolescents are regarded competent regarding decisions relevant to their health from the age of thirteen, while informed consent and assent of the child are gaining importance in the pediatric practice. Along with other national pediatric societies, SAP has underlined the pediatric task to empower child autonomy. ${ }^{1,2}$ In this paper we have focused on the concept of "respect for autonomy" and the relevant challenges in pediatric healthcare.,

First, it is contested from which age autonomy is sufficiently developed for children's decisions to be respected. Second, the classical dipole (physician - patient) is replaced by a triangle of actors (child/adolescent, pediatrician, parents). ${ }^{5}$ This is similar to challenges with autonomy when dealing with less autonomous adults, represented by guardians. ${ }^{6}$ In our case though, autonomy is still developing.

Thus, the objective was to present a model depicting developing autonomy in child healthcare. This is meant to be useful to understand normative implications of child autonomy and to facilitate discussion.

\section{METHODS}

We conducted a literature search and carried out a directorial content analysis. ${ }^{7}$ We examined concepts and models that have strongly influenced the conception of autonomy, including the topic of paternalism, defined as overruling autonomy for a person's assumed benefit. We documented relevant information in a corpus and studied the data using digital methods of qualitative analysis, following three study themes: pediatrician-child, parent-child and pediatrician-parent relationship. We limited our study in situations that include these actors interacting within a frame of justice, where legal, human rights-based and distributive justice ${ }^{8}$ as well as the public health $\operatorname{good}^{9}$ are respected.

Further, the model was developed synthesizing the key findings (Figure 1). The model underwent several phases of refinements, 
including a presentation at the meeting of the German Research Foundation's (DFG) Network: “Children's well-being and child-protection: An analysis of the normative principles of children's well-being ${ }^{\prime 10}$ on October $4^{\text {th }}-6^{\text {th }} 2016$ in Göttingen (Germany).

\section{RESULTS}

In the following we presented what we found to be relevant to the study question, ordered according to four themes: a. autonomy and the child's moral completeness, b. the parental role, c. the pediatrician's role and $\mathrm{d}$. beneficence and the medical good.

\section{How complete is complete?}

Autonomy development includes increasing levels of self-governance. Thorough decisions, self-reliance and balancing parental pressure and peer pressure are key elements of this process. ${ }^{11}$ Several authors argue that autonomy and wholeness for the pediatric patient have not been achieved yet. This may be explained either by radical theories that deny the child's moral worth ${ }^{12-14}$ or through the theory of minimal autonomy, which absolutize the importance of chronological age. ${ }^{15}$ The age-driven character may resemble to Piaget's controversial theory of cognitive development. ${ }^{16}$ Interestingly, recent studies on children's decision-making competences suggest that individuals from the age of twelve years shall be judged as competent to provide informed consent. ${ }^{17}$ Thus, intelligence could complement age as key factor in children's competence to consent to research. ${ }^{18}$

Besides, the principle of 'moral equality' presents a revolutionary approach. Indeed, the principle of 'respect to autonomy' not only equalizes the moral worth of the child of any age and the parents, but also of humans of all ages. The parental role is established on the child's natality, on which the child's trust follows and is safeguarded by the parents' respect and love, guiding them to fulfill the child's needs. Denial of the child's moral worth, unintended (child neglect) or intended (child abuse) signals a betrayal. Rather, an agenting child can only be raised once the child's moral autonomy is respected by the parents. ${ }^{19}$

\section{Does authority make a parent?}

Parental authority and family interests influence the extent of a child's autonomy. For instance, overprotective parenting has been reported to weaken the child's capacity for developing autonomy, with varying effects according to the child's age and degree of physical and cognitive abilities. ${ }^{20}$ Considering the relevance of age and intelligence for cognitive development of children, such overprotective parenting styles can only be counterproductive. ${ }^{18}$ On the contrary, open discussions within the family and participation in family focus groups -sometimes even leading to the children questioning their parents' choices- can be an important means of developing autonomy. ${ }^{21}$

Parenting styles vary from absolute authoritarian paradigms $\mathrm{s}^{12,14}$ to stewardship ${ }^{22}$ and libertarian concepts. ${ }^{19}$ The first ones, comprising expressions of moral adultism, may even conclude that children are parental property, and parents for instance may even decide if their infants should keep living. ${ }^{12}$ Modern libertarian parenting concepts, however, are based on the principle of trust and the respect of the child's equal moral worth. ${ }^{19}$

\section{The role of the pediatrician}

The dynamic pediatrician-child relationship is based on guidance and cooperation. Thus, the pediatrician may show a higher or lower level of authority, resulting in stronger or weaker forms of medical paternalism, from authoritarian, coercive, limited, to libertarian. ${ }^{23}$

According to traditional paternalism models, the physician acts for the patient's good (beneficence), and is qualified to act on behalf of the patient, even without the patient's consent or in opposition to his or her uttered will. A passive patient merely recognizes the physician's authority..$^{24}$ However, the paradigm shift to a less paternalistic medical behavior leads to varying levels of activity and passivity of both actors. In this context, paternalism can be directly associated with the extent of the child's autonomy. Authoritarian paternalism is less likely to boost decision-making competences. Libertarian paternalism though, is the force that intensively facilitates mutual pediatrician-child participation in decision-making, maximizing the child's capacity to be autonomous. ${ }^{25}$ Pellegrino underlines that the pediatrician-patient relationship is about restoring lost wholeness and autonomy. ${ }^{26}$ Indeed, the pediatrician not only should facilitate a restoration, but also stimulate the further autonomy development, especially because illnesses existentially limit children's autonomy. 
Further, informed assent and consent are important tools deriving from libertarian paternalism, facilitating pedagogically the child's agenting role. ${ }^{27,28}$ This role is based on the fact that children are capable of moral feelings at every age, and can act in accordance with them in ways that others can understand and share. ${ }^{19}$ Thus, the pediatrician has an obligation to explain using age-appropriate terminology and to ask for assent of competent children and adolescents. ${ }^{29}$

Furthermore, pediatricians co-coordinate the parent-child interaction. ${ }^{30}$ Focusing on the child within its family, pediatricians facilitate the interdisciplinary work needed to assist autonomystrengthening parenting. ${ }^{31}$ This shall not lead to a compensating rise of medical paternalism. Apart from obligations to the "emerging adult", pediatricians have obligations towards the parents, including openness to discussion, consent or even negotiating responsibilities among family members, or the care-giving team and the parents. ${ }^{29,32}$ Thus, rights deriving from parental authority, rights of new parents and the child's autonomy need to be well balanced when juxtaposed. ${ }^{33}$

Finally, the pediatrician's role is critical in cases of absolute irreconcilability between parents and children. Indeed, it is crucial to have the right to request an intervention of the local agency for child and youth welfare, to consult an ethics committee, or even to initiate a legal intervention. ${ }^{1}$ Pediatricians though, do not always enjoy adequate societal and legal support, that would allow them to utilize such tools. ${ }^{2}$

\section{Medical good}

Beneficence and non-maleficence ${ }^{26}$ are argued to be drivers for paternalism. In healthcare setting, child, physician and parents are freely interacting for the medical good of the first. ${ }^{19}$ Thus, all actors aim at the maximization of net benefits and minimization of net harms dictated by different motives. Fiduciary interest is the driving force of the pediatrician and the parents, while self-interest is the respective child's motive. ${ }^{4}$

\section{Drawing the model}

The terminology describing autonomy development varies in the literature, depicting differences in the stance of academicians. In fact, the terms 'future' and 'developing' autonomy are often used interchangeably. In our opinion, this is not fully correct. 'Future' autonomy is static, illusionary, ignoring the child by simply referring to the adult-to-be. Deriving from moral adultism, it does not represent the kind of autonomy that should be prioritized. On the contrary, 'developing' refers to a dynamic process leading to autonomy through trust and care, guidance and cooperation. Aim should not be the mere preparation for an autonomous adulthood, but the safeguarding of autonomy every step of the way from infancy, through adulthood.

Further, two main and somehow contradicting ideas associated with autonomy are depicted in the literature. First, reflecting the idea of Kantian autonomy, the concept of autonomy refers to the absolute value of the autonomous individual. ${ }^{19}$ The second one reflects the age-driven process of competent decision-making development, as presented by Beauchamp and Childress. ${ }^{3}$

Thus, is chronological age that relevant for the autonomy development? In our opinion, the child's developmental age, summarizing the factors of age and cognitive development, could be the key to assess the development of functions associated with autonomy, such decision-making competences. For this reason, we have included both ideas in the model (Figure 1) using the moral equality axis, pronouncing that all children have the same moral value despite their different competences, as well as the "developmental age"-driven decision-making competence axis. Future research shall consider the children's developmental, and not chronological age, utilizing appropriate assessing tools.

Attempting to graphically display different levels of paternalism against the extent of autonomy, utilizing a guidance-cooperation line as the main axis, we realized that libertarian paternalism shall be the paradigm to actively promote the children's developing autonomy. Pediatricians shall cooperate with the parents to empower young patients in their voyage to autonomy.

While applying the model, a series of conditions needs to be addressed. Pellegrino classified them as contextual, existential, conceptual, and socio-ethical. ${ }^{26}$ Relevant emerging topics to be considered are summarized in Table 1 .

\section{Implementation}

In the following two cases that pronounce different aspects, we have exemplified autonomyrelated challenges, discussing them along the different constructed conditions as laid out in the model. 


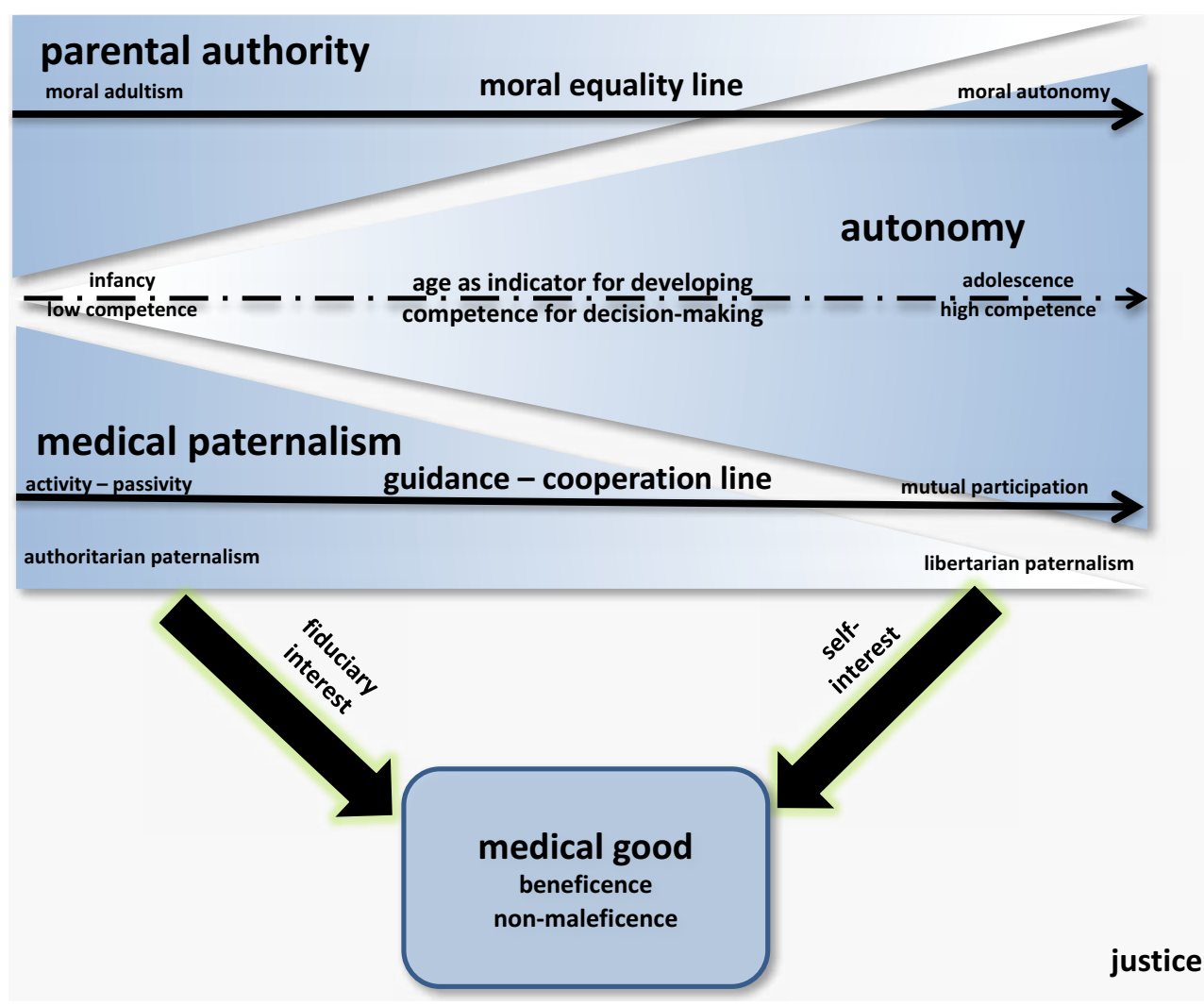

TABLE 1. Exemplary conditions to be addressed when applying the model

\section{Contextual conditions}

- Context variability:

- Nature of the disease, curability, urgency, prognosis and consequences for the child's developing autonomy.

- Properties of the offered diagnostics or therapy and consequences for the child's developing autonomy.

- Alternative therapies or diagnostic methods to be offered and consequences for the child's developing autonomy.

- Health-literacy level of the child and the parents.

- Decision-making competences of the child and the parents.

- Consider the pitfall of false generalizations.

Existential conditions

- How the disease itself may change the ideas and the decision-making competence of the child and the parents.

- How the treatment as well as the alternative treatments may change the ideas and decision-making competence of the child or the parents.

- The effect of prior knowledge or exposition to the disease or therapy on the health-literacy level of the child and the parents.

- Consider institutional or societal differences that have implications on the transferability of a treatment or therapy in another setting.

Conceptual conditions

- Paradigm shift: from cure to care and how is it applied in the case.

- Respect for non-maleficence, if not for beneficence of the child and the family.

- Respect for evidence based medicine when setting indications.

Socio-ethical conditions

- Are there concerns that the individual good, the medical good are suffering from the common good?

- Are there concerns regarding the interest of the parents?

- Are there concerns regarding the motives of the child?

- Are there concerns regarding the exposition of family history or third-party information?

- Are there ethical concerns about the financing of the treatment or diagnostics? Who bears the cost?

- Is there a case of absolutization of autonomy?

- Is there the case of acting without respecting the frame of justice (legal, human rights-based and distributive)? 


\section{Case 1: Influenza vaccine}

Veronica is a ten-year-old girl. Her best friend Mariella, a patient with spinal muscle atrophy (SMA) type III, suffers often from critical infections of the lower respiratory tract. Veronica always visits Mariella during her hospital stays. Veronica wishes to receive the intramuscular seasonal influenza vaccine, because she is convinced that increasing herd immunity is critical for patients like Mariella. Her parents are skeptical about the vaccination.

Contextual conditions: The pediatrician shall first address issues of context variability. The disease itself may be relevant for Veronica. Nevertheless, the consequences among healthy children are limited. The vaccine side-effects are harmless, including mild infections of the respiratory tract and fever, most probably not threatening her developing autonomy. Alternative intranasal vaccines have not been proven effective. Providing evidence based information will rule our health literacy problems. The decision-making competences of the child and parents may be examined using standardized tools. The literature suggests that a ten-year-old child is not always competent to reason wisely in this context.

Existential conditions: On the other hand, Veronica's exposition to influenza-related hazard among SMA patients has increased her awareness. During the discussion with Veronica the pediatrician ruled out doubts regarding her decision-making competence. Chronological age is apparently not the leading dimension.

Veronica is a healthy individual, thus, no relevant concerns regarding the vaccination emerge. According to national recommendations, the vaccine should be provided annually to all children from the second till the sixth year of life.

Conceptual conditions: The case most definitely addresses the paradigm shift from cure to care. The vaccination can effectively increase herd immunity and Veronica's good is not in danger.

Further, Veronica's parents express concerns regarding her school absenteeism. It looks like Veronica has often failed attending school in the last weeks. Currently her school attendance is regular. The mother is worried, that Veronica may get fever and need to stay at home following the vaccination. Veronica may fail to finish the class, in case the school absenteeism emerges again.

Socio-ethical conditions: The pediatrician shall thoroughly address school absenteeism that endangers Veronica's developing autonomy. No concerns about the parents' interest are raised. Veronica's motives though, shall be re-evaluated, probably discussing with her alone. Veronica regrets failing to visit school, and confirms solidarity as her only motive. She would be happy to receive the vaccine during winter holidays, so that she may not need to miss school because of an infection following the vaccination.

Veronica wants to finance the vaccine herself, using pocket money she and Mariella have collected. Except from the fact that the pediatrician now knows about Mariella's condition, there is no additional concern regarding the exposition of family history or third-party information. The frame of justice has always been respected.

Thus, we would conclude that the mutual participation of the pediatrician and the child according to the relationship of guidancecooperation, led to a compromise, that boosts Veronica's autonomy, since her school participation has not been endangered and that she financially contributes for the treatment. The parents' concerns have been taken into serious consideration and were resolved efficiently. Their final decision reflects an acceptance of Veronica's agenting function.

\section{Case 2: Human papilloma virus vaccine}

Human papilloma virus - HPV-driven cancer is frequent in women of reproductive age. Since 2011 the HPV vaccine is offered as part of the national vaccination program in Argentina and the coverage rate is high. ${ }^{34}$ Wenzeslava is a fifteen-year-old migrant girl from Bulgaria. Her family moved to Argentina a few months ago. Her parents wish that she receives the vaccine. She refuses though, arguing that she is not sexually active yet. In a private talk with the pediatrician, she admits being scared of potential side-effects. Wenzeslawa has heard that a girl in Bulgaria developed a lethal Wegener's granulomatosis after HPV immunization. Although there was no causal relation between the two events, vaccination criticism in the media has strengthened the already high vaccine skepticism ${ }^{35}$ in Bulgaria.

The conditions to be addressed have been summarized in Table 2.

In this case we identify issues of health illiteracy, fear induced by anti-vaccination attitudes in media, regarding a vaccine against a sexually transmitted agent, problems regarding the intercultural interaction, language barriers and probably lack of trust towards her new pediatrician. All these shall be thoroughly addressed by the pediatrician. The parents 
understand the indication and back the treatment. On the other hand, Wenzeslawa's argument of not being sexually active yet, shall not be ignored. The girl is in an age that she is regarded, and most probably she is, competent of taking such decisions.

A negotiation seems appealing. The pediatrician shall inform about vaccine benefits and risks and plan an appointment to re-evaluate the situation for instance six months later. It shall be underlined that it is absolutely advisable for her to be immunized by the time she intends to be sexually active. The parents shall be already informed that in such a case, the vaccine may be applied even without their involvement.

\section{CONCLUSIONS}

We introduced a model to explore issues of developing autonomy and the tension with paternalism, driven by both pediatric and parental authority. This model shall support the interdisciplinary dialogue between involved actors, such as pediatricians, public health practitioners, ethicists, parents as well as the children themselves. Contextual, existential, conceptual, and socio-ethical conditions should be critically considered when applying the model.

\section{Acknowledgement}

We are grateful to the participants of the annual conference of the project "Children's well-being and child-protection: An analysis of the normative principles of children's wellbeing" (Göttingen, 4-6 Oct. 2016) for feedback on an earlier draft of this model. We are thankful to Dr. Kruthika Thangavelu, Dr. Mahima Venkateswaran as well as PD Dr. Veronica Maurino for their support.

\section{TABLE 2. Case study: Human papilloma virus vaccine}

\section{Contextual conditions}

- HPV-driven cancers present a serious risk for an often not adequately curable condition, that can be effectively prevented with the HPV vaccine.

- The vaccine coverage is high in Argentina. It is expected to lead to a significant increase of the herd immunity in the coming decades.

- Prevention of vaginal transmission, e.g. using condoms, often does not prevent from oropharyngeal manifestations.

- Sexual inactivity or abstinence is presented as alternative from the girl herself. However, this alternative is definitely restrictive for her future personal and social development, as well as her developing autonomy.

- In this case, health illiteracy-driven fear is the apparent problem.

- The private talk with the pediatrician is a very important tool to be utilized in such cases.

\section{Existential conditions}

- There is no underlying condition or prior experience that could influence the girl's decision-making competence or level of autonomy.

- Wenzeslawa has no prior exposition to HPV-driven diseases. She has been exposed though to false information regarding potential side-effects of the vaccine.

- There are apparent societal differences between the two settings. The HPV vaccine is a successfully implemented program in Argentina, but this is not always the case in a lot of other countries. Problems in the communication or lack of trust, associated with the intercultural character of this pediatrician-patient interaction need to be addressed very thoroughly.

\section{Conceptual conditions}

- The respect for non-maleficence of the girl is crucial. Wenzeslawa needs to be reassured, that the side-effect she is scared for is not associated with the HPV vaccine. However, she shall be informed about all true side-effects, including the extremely rare serious ones.

- The prevention of HPV-driven cancers reflects the respect for beneficence as well as for evidence based medicine.

- Apparent paradigm shift from cure to care. Wenzeslawa shall not be vaccinated for the sake of performing the treatment immediately. She shall understand the personal and societal benefits of this decision and she may receive it in the future.

- Negotiation with the girl could be a useful tool.

Socio-ethical conditions

- There are no concerns that the individual good, or the medical good are suffering from the common good.

- There are no concerns regarding the interest of the parents or the motives of the child.

- There are no concerns regarding the exposition of family history or third-party information.

- There are no concerns about the financing of the treatment or diagnostics.

- There is no case of absolutization of autonomy and the frame of justice has always been respected. 


\section{REFERENCES}

1. Subcomisión de Ética Clínica. Sociedad Argentina de Pediatría. The principle of autonomy in pediatrics under the new Civil and Commercial Code of the Nation: a communication of the Subcommittee on Clinical Ethics. Arch Argent Pediatr 2016;114(5):485-8.

2. Gahr M. Patientenverfügungen von Minderjährigen. Monatsschr Kinderheilkd 2015;163(4):375-378.

3. Beauchamp TL, Childress JF. Principles of biomedical ethics. $7^{\text {th }}$ ed. Oxford: Oxford University Press; 2013.

4. O'Neill O. Autonomy and trust in bioethics. J R Soc Med 2002;95(8):423-4.

5. Carse AL, Nelson HL. Rehabilitating care. Kennedy Inst Ethics J 1996;6(1):19-35.

6. ElliottBA, GessertCE, Peden-McAlpine C. Family decisionmaking in advanced dementia: narrative and ethics. Scand J Caring Sci 2009;23(2):251-8.

7. Hsieh HF, Shannon SE. Three approaches to qualitative content analysis. Qual Health Res 2005;15(9):1277-88.

8. Gillon R. Medical ethics: four principles plus attention to scope. BMJ 1994;309(6948):184-8.

9. O'Neill O. Public health or clinical ethics: thinking beyond borders. Ethics Int Aff 2002;16(2):35-45.

10. Bagattini A. DFG-Projekt: Kindeswohl und Kinderschutz - Analyse der normativen Grundlagen des Kindeswohls. 2017. [Consulta: 15 de noviembre de 2017] Disponible en: http: / / gepris.dfg.de/gepris/projekt/ 263376822.

11. Russell ST, Bakken RJ. Development of autonomy in adolescence. Cooperative Extension, Institute of Agriculture and Natural Resources, University of Nebraska-Lincoln; 2002. [Consulta: 15 de noviembre de 2017] Disponible en: http:/ / www.basicknowledge101. com/pdf/Development $\% 20$ of $\% 20$ Autonomy $\% 20$ in $\% 20$ Adolescence.pdf

12. Giubilini A, Minerva F. After-birth abortion: why should the baby live? J Med Ethics 2013:39(5):261-3.

13. Schapiro T. What Is a Child? Ethics. 1999;109(4):715-38.

14. Tristram E. The foundations of bioethics. $2^{\text {nd }}$ ed. Oxford: Oxford University Press; 1996.

15. Jaworska A. Caring, minimal autonomy, and the limits of liberalism. In: Lindemann $\mathrm{H}$, Verkerk $\mathrm{M}$, Walker $\mathrm{M}$ eds. Naturalized Bioethics: Toward Responsible Knowing and Practice. Cambridge: Cambridge University Press, 2009: 80-105.

16. Piaget J. Piaget's theory. In: Mussen P (ed). Handbook of child psychology. $4^{\text {th }}$ ed. New York: Wiley; 1983.

17. Hein IM, De Vries MC, Troost PW, et al. Informed consent instead of assent is appropriate in children from the age of twelve: Policy implications of new findings on children's competence to consent to clinical research. BMCMed Ethics 2015;16(1):76.
18. Hein IM, Troost PW, Lindeboom R, et al. Key factors in children's competence to consent to clinical research. BMC Med Ethics 2015;16(1):74.

19. Wiesemann C. Moral Equality, Bioethics and the Child. Switzerland: Springer; 2016.

20. Affdal AO, Moutard ML, Billette de Villemeur T, et al. Le difficile passage à l'âge adulte en matière de soins: l'exemple de l'épilepsie. Arch Pediatr 2015;22(4):337-42.

21. NicholJ, Thompson EA, Shaw A. Beliefs, decision-making, and dialogue about complementary and alternative medicine (CAM) within families using CAM: a qualitative study. J Altern Complement Med 2011;17(2):117-25.

22. Brennan S, Noggle R. The moral status of children: Children's rights, parents' rights, and family justice. Soc Theor Pract 1997;23(1):1-26.

23. Strasser M. The new paternalism. Bioethics 1988;2(2):103-17.

24. Komrad MS. Adefence of medical paternalism: maximising patients' autonomy. J Med Ethics 1983;9(1):38-44.

25. Karlsson K. Handling dilemmas of self-determination in 'user-centred' rehabilitation. Disabil Rehabil 2007;29(3):245-53.

26. Pellegrino ED, Thomasma DC. The conflict between autonomy and beneficence in medical ethics: proposal for a resolution. J Contemp Health Law Policy 1987;3:23-46.

27. Kuther TL, Posada M. Children and adolescents' capacity to provide informed consent for participation in research. Adv Psychol Res 2004;32:163-73.

28. Rossi WC, Reynolds W, Nelson RM. Child assent and parental permission in pediatric research. Theor Med Bioeth 2003;24(2):131-48

29. Sibley A, Pollard AJ, Fitzpatrick R, et al. Developing a new justification for assent. BMC Med Ethics 2016;17:2.

30. Simpson C. Supporting the Developing Autonomy of Youth Patients: Reflections on the Role of Healthcare Providers. In: Zlotnik Shaul R. (ed). Paediatric Patient and FamilyCentred Care:Ethical and Legal Issues. New York: Springer; 2014:175-84.

31. Harrison C, Kenny NP, Sidarous M, et al. Bioethics for clinicians: 9. Involving children in medical decisions. CMAJ 1997;156(6):825-8.

32. Kloep M, Hendry LB. Letting go or holding on? Parents' perceptions of their relationships with their children during emerging adulthood. Br J Dev Psychol 2010;28(Pt 4):817-34.

33. Goering S. Postnatal reproductive autonomy: promoting relational autonomy and self-trust in new parents. Bioethics 2009;23(1):9-19.

34. Patel H, Wilson E, Vizzotti C, et al. Argentina's Successful Implementation Of A National Human Papillomavirus Vaccination Program. Health Aff(Millwood) 2016;35(2):301-8.

35. Petrova D, Brunton CG, Jaeger M, et al. The Views of Young Women on HPV Vaccine Communication in Four European Countries. Curr HIV Res 2015;13(5):347-58. 